\title{
PELAKSANAAN PEMBIASAAN GERAKAN LITERASI SEKOLAH DI SDN 009 LUBUK AGUNG
}

\author{
Radani Suslawati ${ }^{1}$, Febrina Dafit $^{1}$ \\ ${ }^{1}$ Universitas Islam Riau Pekanbaru, Riau \\ *Corresponding Address: radanisuslawati@gmail.com
}

Naskah diterima: 1 Desember 2021| Disetujui: 6 Desember 2021 | Diterbitkan: 7 Desember 2021

\begin{abstract}
Good literacy skills can help students understand information both verbally and in writing. The implementation of the habituation of the School Literacy Movement is one of the literacy activities and a form of government awareness of the importance of building a literacy culture in the world of education. This study aims to describe the implementation of the habituation of the School Literacy Movement at SDN 009 Lubuk Agung, Kampar Regency. This research is a descriptive qualitative research. The subjects of this study were 1 principal and 6 homeroom teachers. Research instruments in the form of interviews, observations and documentation. The data analysis technique in this study is the presentation of data and drawing conclusions. Based on the results of the study, it shows that the habituation of the School Literacy Movement has not been carried out well, this can be seen from the results of the interviews that reading has not been carried out 15 minutes before the lesson starts, the school facilities and environment are not yet rich in literacy, and also not rich in text, cannot choose reading materials in the classroom. schools, and also not involving the public.
\end{abstract}

Keywords: Implementation, School Literacy Movement

\begin{abstract}
Abstrak: Kemampuan literasi yang baik dapat membantu siswa dalam memahami informasi baik lisan maupun tulisan. Pelaksanaan pembiasaan Gerakan Literasi Sekolah merupakan salah satu kegiatan literasi dan bentuk kesadaran pemerintah terhadap pentingnya membangun budaya literasi dalam dunia pendidikan. Penelitian ini bertujuan untuk mendeskripsikan pelaksanaan pembiasaan Gerakan Literasi Sekolah di SDN 009 Lubuk Agung Kabupaten Kampar. Jenis penelitian ini adalah deskriptif kualitatif. Subjek penelitian ini adalah 1 orang kepala sekolah dan 6 wali kelas. Instrument penelitian berupa wawancara, observasi, dan dokumentasi. Teknik analisis data dalam penelitian ini adalah dengan penyajian data dan penarikan kesimpulan. Berdasarkan hasil penelitian menunjukkan bahwa pembiasaan Gerakan Literasi Sekolah belum terlaksana dengan baik. Hal ini terlihat dari hasil wawancara yaitu belum terlaksananya membaca 15 menit sebelum pelajaran dimulai, sarana dan lingkungan sekolah belum kaya akan literasi, belum kaya akan teks, tidak bisa memilih bahan bacaan di sekolah, dan belum melibatkan publik.
\end{abstract}

Kata kunci: Pelaksanaan, Gerakan Literasi Sekolah 


\section{PENDAHULUAN}

Pendidikan merupakan salah satu yang sangat penting dalam kehidupan manusia, dengan ilmu pengetahuan yang didapat dari pendidikan, manusia mampu merubah segala aspek kehidupan. Pendidikan juga mampu memajukan suatu bangsa dan negara. Pendidikan merupakan salah satu indikator keberhasilan pembangunan suatu negara. Hal ini dikarenakan pendidikan merupakan proses dalam membentuk sumber daya manusia yang berkualitas (Siti, et.al., 2017). Menurut Undangundang No. 20 Tahun 2003 tentang Sistem Pendidikan Nasional dalam Bab 2 Pasal 3 bahwa pendidikan nasional berfungsi mengembangkan kemampuan dan membentuk watak serta peradaban bangsa yang bermartabat dalam rangka mencerdaskan kehidupan bangsa, bertujuan untuk berkembangnya potensi peserta didik agar menjadi manusia yang beriman dan bertakwa kepada Tuhan Yang Maha Esa, berakhlak mulia, sehat berilmu, cakap, kreatif, mandiri, dan menjadi warga negara yang demokratis serta bertanggung jawab. Menurut Mitasari, ketika seorang anak memiliki kemampuan literasi, maka anak tersebut juga memiliki kemampuan berbahasa yang baik (Mitasari, 2017).

Agar dapat memahami pembelajaran membaca dan menulis pada siswa sekolah dasar, pemerintah mengeluarkan terobosan melalui Gerakan Literasi Sekolah (GLS). Gerakan Literasi Sekolah merupakan upaya yang dilakukan untuk menjadikan seluruh warga sekolah menjadi warga yang literat sepanjang hayat (Fakar, 2018). Ada hal yang dapat mempengaruhi keberhasilan program gerakan literasi ini, yaitu jumlah buku yang ada di perpustakaan sekolah masih sangat terbatas, sehingga buku yang ingin siswa baca tidak sesuai dengan seleranya (Yunianika dan Surtinah, 2019). Maka dari itu penting adanya kerja sama yang baik dari pemerintah, lingkungan sekolah, keluarga, serta saling mendukung dalam kegiatan literasi agar terlaksana dengan baik. Jika hanya satu pihak saja yang menginginkan terwujudnya kegiatan literasi serta tidak adanya kolaborasi dengan pihak lain, maka tidak akan terlaksana dengan baik kegiatan literasi tersebut. Adapun menurut Goody, pengertian literasi dalam arti sempit adalah kemampuan untuk membaca dan menulis (Malawi, 2017).

Literasi sekolah dalam konteks GLS adalah kemampuan mengakses, memahami, dan menggunakan sesuatu secara cerdas melalui berbagai aktivitas, antara lain membaca, melihat, menyimak, menulis, dan/atau berbicara (Antasari, 2017). Gerakan Literasi Sekolah adalah salah satu langkah untuk membudidayakan kegiatan membaca dan menulis dalam rangka meningkatkan minat baca yang ada di sekolah, sehingga akan berdampak pada kemampuan siswa dalam berliterasi sejak dini (Fauziah dan Lestari, 2018). Pelaksanaan GLS terdiri dari 3 tahapan, yaitu tahap pembiasaan, pengembangan, dan pembelajaran (Suyono, 2017). Ada beberapa kendala dalam pelaksanaan GLS, di antaranya 1) Beberapa warga sekolah masih banyak yang kurang mendukung GLS ini dan belum 
menyadari tanggung jawabanya. 2) Peserta didik memiliki latar belakang yang jauh dari budaya literasi. 3) Unsur penunjang keberhasilan ini adalah perpustakaan yang masih belum lengkap (Agustin dan Cahyono, 2017). Menurut Zakiyah, tahap pembiasaan GLS dapat dilihat dari indikator-indikator berikut:

a. Membaca 15 menit sebelum pelajaran dimulai

Membaca 15 menit sebagai sarana menumbuhkan literasi dan pembiasaan membaca kepada peserta didik. Buku yang dibaca adalah buku non pelajaran. Teknisnya bisa dibaca dengan nyaring atau bisa dibaca dalam hati.

b. Penataan lingkungan yang kaya literasi

Penataan lingkungan yang kaya literasi sangat membantu dalam membentuk generasi literat. Sarana dan lingkungan literasi tersebut adalah perpustakaan, buku, sudut buku kelas, UKS, kantin dan lain-lain.

c. Menciptakan lingkungan kaya teks

Menciptakan lingkungan kaya teks bisa dilakukan dengan menempelkan label, kata motivasi, peraturan kelas, poster, dan lain sebagainya.

d. Memilih buku bacaan di Sekolah Dasar (SD)

Buku yang disediakan adalah buku yang sesuai dengan karakter siswa sekolah dasar, baik buku cerita, buku ilmiah yang dikemas dalam bentuk cerita, dan lain-lain. Siswa membaca buku yang disukai yang disediakan sekolah atapun siswa membawa sendiri buku yang mereka sukai untuk dibaca. Pada usia ini, anak terdorong dengan kesukaaan kepada buku-buku sains atau lingkungan sekitarnya. Buku-buku non fiksi dengan ilustrasi gambar yang menarik juga sangat disenangi oleh anak-anak usia dasar.

e. Pelibatan publik

Pelibatan publik dalam mewujudkan sekolah yang literat sangat penting dilakukan baik dari partisipasi pemerintah, instansi pendidikan, orang tua siswa, dan komunitas lain yang mendukung jalanya GLS (Zakiyah, 2018).

Dari hasil wawancara dengan salah satu guru di SDN 009 Lubuk Agung Kabupaten Kampar pada September 2021, terdapat permasalahan berkaitan dengan keterlaksanaan GLS yang masih belum maksimal dikarenakan kurangnya fasilitas sarana dan prasarana yang memadai. Tujuan penelitian ini secara umum adalah mengetahui bagaimana pelaksanaan pembiasaan Gerakan Literasi Sekolah di SDN 009 Lubuk Agung Kabupaten Kampar. Penelitian ini bertujuan untuk mendeskripsikan pelaksanaan pembiasaan Gerakan Literasi Sekolah di SDN 009 Lubuk Agung Kabupaten Kampar. 


\section{METODE}

Penelitian ini menggunakan pendekatan kualitatif yang bersifat deskriptif. Menurut Anggito dan Setiawan, penelitian kualitatif adalah pengumpulan data pada suatu latar belakang ilmiah dengan maksud menafsirkan fenomena yang terjadi di mana peneliti adalah instrumen kunci (Anggito dan Setiawan, 2018). Kualitatif adalah jenis penelitian yang digunakan untuk menguji hipotesis dengan data berupa kata-kata, dan juga dapat mengumpulkan seta menganalisis data yang bersifat naratif (Sugiyono, 2020). Deskriptif adalah data yang dikumpulkan berupa kata-kata, gambar, dan bukan angka-angka (Mamik, 2015). Penelitian ini di lakukan di SDN 009 Lubuk Agung, Kecamatan Kampar Kiri, Kabupaten Kampar. Subjek dalam penelitian ini adalah kepala sekolah dan 6 orang wali kelas. Dalam penelitian kualitatif, instrumen utamanya adalah peneliti sendiri. Namun instrumen pendukung dalam penelitian ini yaitu observasi, wawancara, dan dokumentasi. Pedoman observasi dalam penelitian ini dilakukan dengan cara mengamati perilaku tersebut di lapangan untuk mempermudah dalam menggali data yang didapat dari lapangan, wawancara digunakan untuk mengumpulkan data dan menggali informasi tentang pelaksanaan pembiasaan Gerakan Literasi Sekolah sebagai bahan untuk analisis data dan penarikan kesimpulan. Dokumentasi yang digunakan dalam penelitian ini adalah dokumentasi kegiatan pembiasaan GLS yang ada di sekolah yang berupa foto sarana yang mendukung pelaksanaan GLS, foto wawancara dengan kepala sekolah, dan foto dengan guru wali kelas.

Prosedur dalam penelitian ini adalah mengumpulkan data, mereduksi data, dan penarikan kesimpulan. Sumber data dari penelitian ini, yaitu observasi, wawancara, dan dokumentasi. Data yang dihasilkan dari wawancara diuraikan dengan kata-kata atau kalimat dan ditarik kesimpulan. Analisis data dalam penelitian ini adalah peneliti mengumpulkan data yang diperoleh dari wawancara dalam penelitian ini berupa data kualitatif yang bersifat deskriptif. Menurut Siyoto dan Sodik, data adalah sesuatu yang belum mempunyai arti bagi penerimanya dan masih memerlukan adanya suatu pengolahan (Siyoto dan Sodik, 2015). Berdasarkan sumbernya, data penelitian ini dibagi menjadi 2, yaitu data primer dan data sekunder. Data primer adalah data yang dikumpulkan atau diperoleh oleh peneliti secara langsung dari sumber datanya. Data sekunder adalah data yang diperoleh atau yang dikumpulkan peneliti dari berbagai sumber. Menurut Miler dan Huberman, peneliti sebagai instrumen yang mengumpulkan data kemudian mereduksi data dengan memilih hal-hal yang pokok, merangkum, dan memberikan gambaran yang lebih jelas, selanjutnya peneliti menampilkan data dalam bentuk uraian singkat. Hasil akhir dari penelitian ini penarikan kesimpulan (Sugiyono, 2020). 


\section{HASIL DAN PEMBAHASAN}

\section{Pelaksanaan Pembiasaan GLS di SDN 009 Lubuk agung}

Berdasarkan hasil penelitian yang dilakukan di SDN 009 Lubuk Agung, Kabupaten Kampar mengenai pelaksanaan pembiasaan GLS, diketahui berdasarkan indikator pembiasaan GLS seperti membaca 15 menit sebelum pelajaran dimulai, menata sarana dan lingkungan kaya literasi, menciptakan lingkungan kaya teks, memilih buku bacaan di SD, dan pelibatan publik. Untuk memperoleh gambaran pembiasaan GLS, maka peneliti perlu melakukan observasi dan wawancara untuk memperoleh data.

Hasil wawancara dengan kepala sekolah dan guru wali kelas 1-6 secara keseluruhan menyimpulkan bahwa pelaksanaan pembiasaan GLS belum terlaksana dengan baik. Dari hasil observasi yang dilakukan langsung oleh peneliti di SDN 009 Lubuk Agung, kegiatan membaca 15 menit sebelum pelajaran dimulai dilaksanakan dengan menggunakan buku non pelajaran seperti buku tema, tidak terlihat penataan sarana dan lingkungan sekolah yang kaya akan literasi, belum tercipta lingkungan yang kaya akan teks, serta tidak tersedia bahan bacaan non pelajaran yang dapat dipilih siswa sesuai yang disukainya, dan juga belum ada pelibatan dari publik.

Dari hasil wawancara yang dilakukan dengan kepala sekolah dan para wali kelas, mulai dari wali kelas satu sampai dengan wali kelas enam diperoleh informasi mengenai pelaksanaan pembiasaan GLS di SDN 009 Lubuk Agung berdasarkan indikator pembiasaan GLS sebagai berikut: Tidak Menggunakan Buku Non Pelajaran untuk Kegiatan Membaca 15 Menit Sebelum Pembelajaran Dimulai

Kegiatan membaca 15 menit sebelum pelajaran dimulai dilaksanakan dengan menggunakan buku pelajaran dan tidak pernah menggunakan buku non pelajaran seperti buku dongeng, buku cerita bergambar, atau buku yang lainnya sesuai minat anak. Pada saat peneliti melaksanakan observasi, peneliti melihat langsung buku yang mereka gunakan untuk kegiatan membaca 15 menit sebelum pelajaran dimulai yaitu buku tema. Siswa kelas 1 , kelas 2 , dan kelas 3 , semuanya membaca buku tema 4. Sedangkan kelas 4, kelas 5, dan kelas 6 mereka membaca buku tema 5. Dari hasil wawancara dengan kepala sekolah dan guru wali kelas, alasan mereka menggunakan buku pelajaran untuk kegiatan membaca karena mereka tidak memiliki buku non pelajaran dikarenakan tidak mempunyai tempat atau ruang khusus seperti perpustakaan untuk menyimpan buku-buku non pelajaran.

\section{Tidak Menata Sarana dan Lingkungan Kaya Literasi}

Sarana dan lingkungan yang ada di SDN 009 Lubuk Agung belum bisa dikatakan sarana dan lingkungan yang literat, adapun saranan yang dimiliki hanya ruang kelas dan kantin saja, dan tidak 
ada ditemukan poster-poster kampanye untuk hidup sehat, kebersihan ataupun yang lainnya di sekitaran kantin. Adapun sarana yang lain seperti perpustakaan, ruang UKS, sudut baca dalam kelas tidak ada. Alasannya dari hasil wawancara dengan kepala sekolah mengatatakan bahwa sekolah tersebut masih kekurangan ruang belajar, sehingga tidak bisa digunakan untuk ruang perpustakaan, UKS, dan yang lainnya. Adapun di dalam kelas mereka tidak ada sudut baca. Hal itu dikarenakan banyaknya siswa dalam satu kelas tersebut sehingga tidak cukup ruang untuk membuat sudut baca dalam kelas. Sudut baca merupakan sudut di ruangan kelas yang digunakan untuk memajang koleksi bacaan dan karya siswa yang fungsinya untuk mendekatkan buku pada siswa dan menumbuhkan minat baca siswa, sehingga buku yang dipajang harus buku yang menarik (Faizah, 2016).

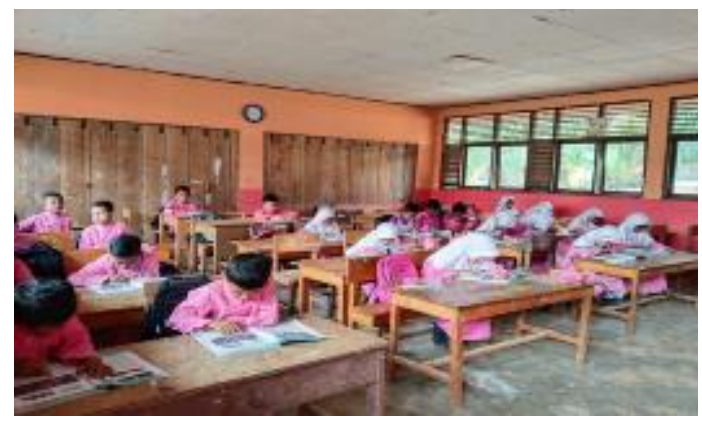

Gambar 1. Ruang kelas yang penuh

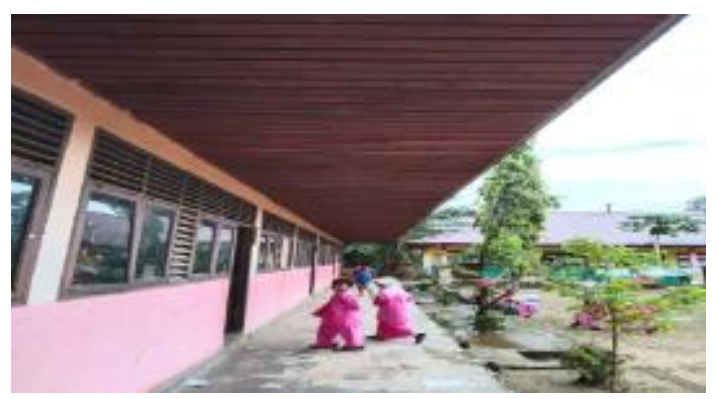

Gambar 2. Koridor kelas 1-3 yang tidak literat

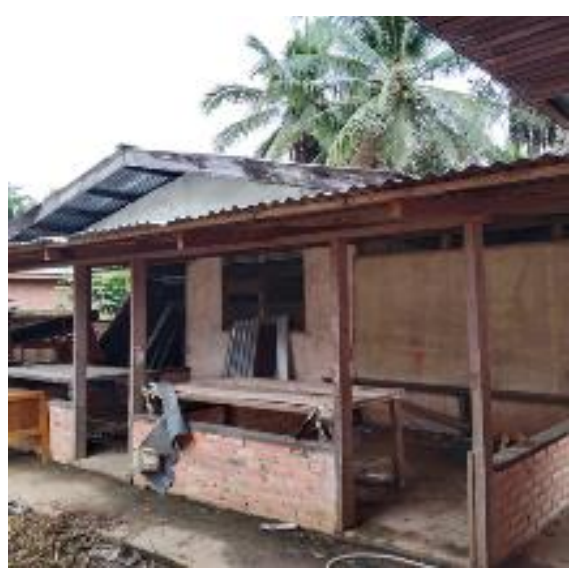

Gambar 3. Kantin sekolah yang tidak literat 


\section{Tidak Terciptanya Lingkungan Kaya Teks}

Dari hasil observasi yang dilakukan oleh peneliti terlihat jelas bahwa di SDN 009 Lubuk Agung tidak terlihat tempelan label di sekitaran lingkungan sekolah, baik kata-kata motivasi, poster tentang kebersihan, kesehatan, dan lain sebagainya. Peneliti juga tidak menjumpai adanya poster-poster yang mengampanyekan ajakan membaca bagi siswa, misalnya saja pada mading sekolah, papan pengumuman, ataupun di tempat-tempat lainnya. Alasan yang didapatkan dari hasil wawancara kepala sekolah dan para guru wali kelas bahwa siswa yang ada di sekolah tersebut terlalu aktif, sehingga suka mencopot tempelan-tempelan label yang sudah dibuat dan suka merobekkan posterposter yang dulu pernah dipasang, sehingga guru enggan untuk membuat kembali dengan alasan mereka merasa tidak akan bertahan lama.

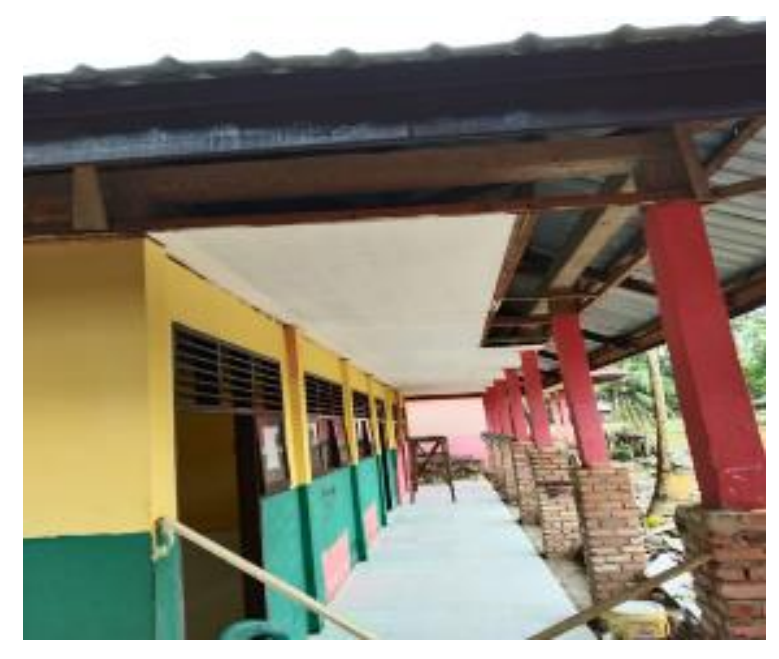

Gambar 4. Koridor kelas 4-6 yang tidak literat

\section{Tidak Dapat Memilih Buku Bacaan di Sekolah}

Dari hasil wawancara yang dilakukan peneliti dengan seluruh wali kelas memperoleh hasil bahwa siswa tidak bisa memilih bahan bacaan sesuai dengan minat dan kesukaan mereka ketika melaksanakan kegiatan GLS, mereka terpaksa membaca buku yang ada di sekolah seperti buku paket dan buku pelajaran. Hal tersebut karena sekolah tidak menyediakan buku non pelajaran karena tidak adanya ruang khusus seperti perpustakaan. Menurut Aisyi, buku yang dibaca dalam pelaksanaan Gerakan Literasi Sekolah adalah buku non pelajaran baik itu buku dongeng, majalah, koran, dan lainnya. Sumber buku meliputi pengadaan dan pemilihan buku, sedangkan lingkungan literasi meliputi area baca, perpustakaan, sudut baca kelas, dan poster (Suyono, et.al, 2017).

\section{Belum Adanya Keterlibatan Publik}

Pelaksanaan GLS di SDN 009 Lubuk Agung belum melibatkan publik seperti dukungan dari orang tua dan juga kegiatan dari alumni sekolah. Alasannya adalah kepala sekolah dan para guru 
belum terfokus dalam pelaksanaan pembiasaan sekolah, sehingga belum melibatkan publik untuk melaksanakan pembiasaan GLS di sekolah mereka.

Sumber daya yang terlibat untuk kebijakan GLS, yaitu manajemen terbuka terhadap masukanmasukan. Dari pihak manajemen dapat disampaikan pada guru-guru. Sehingga kebijakan atau program tidak hanya berasal dari kepala sekolah. Orang tua juga dilibatkan dalam proses ini, sehingga terjadi kolaborasi antara guru dan karyawan (Wandasari, 2017).

Gerakan Literasi Sekolah (GLS) di SD dilaksanakan secara bertahap dengan mempertimbangkan kesiapan masing-masing sekolah. Kesiapan ini mencakup kesiapan kapasitas fisik sekolah (ketersedian fasilitas, sarana dan prasarana literasi), kesiapan warga sekolah (peserta didik, tenaga guru, orang tua, dan komponen masyarakat lainnya), dan kesiapan system pendukung lainnya (partisipasi publik, dukungan kelembagaan, dan perangkat kebijakan yang relevan) (Rohani, 2019).

Adapun menurut Susilawati dan Sulhan menjelaskan bahwa pelaksanaan GLS pada tiga ruang lingkup, yaitu (a) lingkungan fisik sekolah (fasilitas dan sarana prasarana literasi), (b) lingkungan sosial dan lingkungan akademik (program literasi yang menumbuhkan minat baca dan menunjang kegiatan pembelajaran) (Susilawati dan Sulhan, 2018).

Rahmawati menjelaskan adapun tahapan pelaksanaan Gerakan Literasi Sekolah menurut buku saku GLS dibagi dalam tiga tahapan, yaitu tahap pembiasaan, tahap pengembangan, dan tahap pembelajaran. Pada tahap pembiasaan penumbuhan minat baca melalui kegiatan 15 menit membaca. Pada tahap pengembangan dilakukan dengan meningkatkan kemampuan literasi melalui kegiatan menanggapi buku pengayaan, dan pada tahap pembelajaran dapat dilakukan dengan meningkatkan kemampuan literasi pada semua mata pelajaran, menggunakan buku soal dan strategi membaca di semua mata pelajaran. Tujuan GLS salah satunya adalah mengembangkan karakter (Nurkaeti dkk, 2019). Menurut Hastuti dan Lestari, Gerakan Literasi Sekolah dimaksudkan untuk mengajak (Hastuti dan Lestari, 2018).

\section{Kendala dalam Pelaksanaan Pembiasaan GLS di SDN 009 Lubuk Agung}

Pada pelaksanaan Gerakan Literasi Sekolah ditemukan beberapa hambatan-hambatan dalam kegiatan GLS di SDN 009 Lubuk Agung. Kendala yang ditemukan dalam pelaksanaan Gerakan Literasi Sekolah seperti, (1) masalah waktu dalam pelaksanaan kegiatan literasi, (2) berkurangnya bahan koleksi di dalam kelas pada akhir semester, dan (3) berkurangnya komitmen guru dalam melaksanakan pembiasaan membaca di kelas (Novaria dkk, 2019). Adapun kendala dalam pelaksanaan pembiasaan di SDN 009 Lubuk Agung adalah sebagai berikut: 


\section{Rendahnya Tingkat Kesadaran Guru}

Dari hasil wawancara yang telah dilakukan peneliti, para guru yang ada di SDN 009 Lubuk Agung kurang menganggap penting Gerakan Literasi Sekolah. Mereka menganggap bahwa GLS hanya sekadar formalitas saja, sehingga tidak mau memahami dan mempelajarinya lebih dalam, dampaknya mereka tidak paham bagaimana pelaksanaan GLS tersebut. Para guru juga beranggapan tidak mempunyai waktu yang lebih untuk melaksanakan GLS, waktu yang dimaksimalkan habis digunakan untuk pembelajaran di kelas, dan terkadang merekapun kekurangan waktu untuk belajar mengajar. Oleh karena itu, guru kurang fokus menjalan kegiatan tersebut. Kurangnya perhatian dan pembinaan dari pihak dinas pendidikan baik di tingkat kecamatan maupun kabupaten juga sangat mempengaruhi terlaksananya kegiatan GLS di sekolah.

\section{Sekolah Kekurangan Sarana}

Pelaksanaan pembiasaan GLS di SDN 009 Lubuk Agung terkendala oleh kurangnya sarana dan prasarana yang memadai. Fasilitas yang dimiliki oleh SDN 009 Lubuk Agung jauh dari kata cukup dan masih kurang layak untuk menerapkan kegiatan GLS, sarana perpustakaan sebagai salah satu yang sangat penting juga tidak dimiliki oleh sekolah. Ruang kelas yang digunakan untuk belajar setiap harinya juga masih kurang untuk jumlah siswa sebanyak 207 siswa dari total keseluruhan siswa. Total ruang kelas hanya berjumlah ha 6 ruang saja untuk belajar dengan 6 rombel dari kelas satu sampai kelas enam. Tidak ada ruang untuk perputakakaan sebagai penunjang terlaksananya kegiatan GLS, dan tidak ada juga ruang untuk UKS.

Sarana dan prasarana untuk mendukung terlaksananya kegiatan pembiasaan GLS seperti sudut baca di dalam kelas juga tidak dimiliki. Hal tersebut dikarenakan tidak cukupnya ruangan untuk jumlah siswa yang lebih dari 30 siswa dalam satu rombongan belajar. Menurut Rohiat, mengemukakan bahwa sarana dan prasarana adalah semua benda atau barang yang bergerak maupun yang tidak bergerak yang digunakan untuk menunjang terlaksanakannya proses pembelajaran yang langsung maupun yang tidak langsung dalam sebuah pendidikan (Nurbaiti, 2015).

\section{KESIMPULAN}

Berdasarkan hasil penelitian dan pembahasan yang telah diuraikan, dapat ditarik kesimpulan bahwa pelaksanaan pembiasaan Gerakan Literasi Sekolah di SDN 009 Lubuk Agung masih belum terlaksana dengan baik, serta belum terlaksananya semua indikator yang ada pada tahap pembiasaan. Sarana dan prasarana yang tersedia tidak memadai untuk mendukung terlaksananya kegiatan Gerakan Literasi Sekolah di SDN 009 Lubuk Agung Kabupaten Kampar. Faktor pendukung untuk pelaksanaan Gerakan Literasi Sekolah di SDN 009 Lubuk Agung Kabupaten Kampar tidak ada. Ada beberapa 
faktor penghambat untuk pelaksanaan Gerakan Literasi Sekolah di SDN 009 Lubuk Agung Kabupaten Kampar baik dari internal maupun dari eksternal.

\section{DAFTAR PUSTAKA}

Agustin S., \& Cahyono H. E. B. 2017. Gerakan literasi sekolah untuk meningkatkan budaya baca di SMA Negeri 1 Geger. Jurnal Linguista. Vol 1(2):61-62

Antasari, W.I. 2017. Implementasi Gerakan Literasi Sekolah Tahap Pembiasaan di MI Muhammadiyah Gandatapa Sumbang Banyumas. Jurnal Libria, Vol 9(1):14

Anggito A. \& Setiawan J. 2018. Metodologi Penelitian Kualitatif. Jawa Barat: CV Jejak. Ebook (Online)

Aisyi I.R. dkk. 2020. Gerakan Literasi Sekolah: Pelaksanaan, Hambatan, dan Solusi (Study Kasus di SD Ghufron Faqih Surabaya).Vol XI(2):99

Fakar P. S . 2018. Implementasi Kebijakan Gerakan Literasi Sekolah Di Sekolah Dasar Unggulan Aisyiyah Taman Harapan Curup. Skrips (Online). Fakultas Tarbiyah dan Ilmu Keguruan. Program Studi PendidikaN Guru Madrasah Ibtidaiyah. Institut Agama Islam Negeri.

Fauziah G., \& Lestari W. A. 2018. Pembudayaan Gerakan Literasi Informasi Siswa Tingkat Sekolah Dasar Di Tangkerang Selatan. Jurnal Edu lib. Vol 8(2):172

Faizah, D. U, dkk. (2016). Panduan Gerakan Literasi Sekolah di Sekolah Dasar. Jakarta. Kemendikbud.

Hastuti Sunu dan Lestari Agus Nia. 2018. Gerakan Literasi Sekolah: Implementasi Tahap Pembiasaan dan Pengembangan Literasi Di SD Sukorejo Kediri. Jurnal BASA TAKA. Vol $1(2): 30-31$

Mamik. 2015. Metodologi Kualitatif. Sidoarjo:Zifatama Publisher. Ebook (Online)

Malawi Ibadullah, dkk. 2017. Pembelajaran Literasi Berbasis Lokal. Jawa Timur: CV. AE Media Grafika. Ebook (Online)

Mitasari S. L. 2017. Peran Kegiatan Literasi Dalam Meningkatkan Minat Membaca dan Menulis Siswa Kelas Atas Di SDN Gumpang 1. Skripsi (Online). Fakultas Keguruan dan Ilmu Pendidikan. Program Studi Pendidikan Guru Sekolah Dasar. Universitas Muhammadiyah Surakarta. Surakarta

Novarina G. E. dkk. 2019. Model Pelaksanaan Gerakan Literasi Sekolah. Jurnal Pendidikan. Vol $4(11): 1454$ 
Nurbaiti. (2015). Manajemen Sarana dan Prasarana Sekolah. Jurnal Unib, Vol 9(4):536.

Nurkaeti Nunuy, dkk. 2019. Read Loud: An Literacy Activity In Elementery

School. Journal Of Elementary Education. Vol 3(2): 60

Rahmawati. A.D. Weni. R. 2021. Implementasi Gerakan Literasi Sekolah di Sekolah Dasar Negeri Sedati Gede 2 Sedati Kabupaten Sidoarjo. Vol 9(1):26

Rohani. 2019. Penerapan Gerakan Literasi Sekolah Pada Pembelajaran Bahasa Indonesia Di SDN Cot Lheue Rheng, Sain Riset. Vol 9(1):46

Siti, et.al. 2017. Evaluasi Implementasi Kebijakan Pendidikan Gratis di Kabupaten Pasaman. JPSI (Journal of Public Sector Innovations, 2(1), 1-9

Sugiyono. 2020. Metode Penelitian Kualitatif. Bandung: Penerbit Alfabeta

Susilawati dan Sulhan M. 2018. Pelaksanaan Gerakan Literasi Sekolah (GLS) Di Tingkat Sekolah Dasar. Jurnal Visipena. Vol 9(2):264

Siyoto Sandu dan Sodik Ali . 2015. Dasar Metodologi Penelitian. Yogyakarta:

Literasi Media Publishing. Ebook (Online)

Suyono, dkk. 2017. Implementasi Gerakan Literasi Sekolah Pada Pembelajaran Tematik Sekolah Dasar. Jurnal Sekolah Dasar. Vol 26 (2):117

Wandasari. (2017). Implementasi Gerakan Literasi Sekolah (GLS) Sebagai Pembentuk Pendidikan Berkarakter. Tanah Abang: SMK Negeri 1. Vol 1(1).

Undang-Undang No.20 Tahun 2003. Sistem Pendidikan Nasional. Bab 2 Pasal 3

Yunianika Tri Ika dan Suratinah. 2019. Implementasi Gerakan Literasi Sekolah

Di Sekolah Dasar Dharma Karya Universitas Terbuka. Jurnal Ilmiah Sekolah Dasar, Vol 3 (4):49

Zakiyah. 2018. Pelaksanaan Gerakan Literasi Sekolah (GLS) Di SDN Girimoyo 2 Karangploso Kabupaten Malang. Skripsi (Online). Fakultas Keguruan dan Ilmu Pendidikan. Program Studi Pendidikan Guru Sekolah Dasar. Universitas Muhammadiyah Malang. 
PELAKSANAAN PEMBIASAAN GERAKAN LITERASI SEKOLAH DI SDN 009 LUBUK AGUNG Radani Suslawati, Febrina Dafit 